\title{
Optimal point of insertion of the needle in neuraxial blockade using a midline approach: study in a geometrical model
}

This article was published in the following Dove Press journal:

Local and Regional Anesthesia

10 August 2016

Number of times this article has been viewed

\author{
Mark Vogt ${ }^{1}$ \\ Dennis J van Gerwen ${ }^{2}$ \\ John J van den \\ Dobbelsteen ${ }^{2}$ \\ Martin Hagenaars ${ }^{3}$ \\ 'Department of Anesthesiology, \\ Erasmus MC Sophia Children \\ Hospital, Rotterdam, the Netherlands; \\ ${ }^{2}$ Department of Biomechanical \\ Engineering, Delft University of \\ Technology, Delft, the Netherlands; \\ ${ }^{3}$ Department of Anesthesiology, \\ Canisius Wilhelmina Ziekenhuis, \\ Nijmegen, the Netherlands
}

\begin{abstract}
Performance of neuraxial blockade using a midline approach can be technically difficult. It is therefore important to optimize factors that are under the influence of the clinician performing the procedure. One of these factors might be the chosen point of insertion of the needle. Surprisingly few data exist on where between the tips of two adjacent spinous processes the needle should be introduced. A geometrical model was adopted to gain more insight into this issue. Spinous processes were represented by parallelograms. The length, the steepness relative to the skin, and the distance between the parallelograms were varied. The influence of the chosen point of insertion of the needle on the range of angles at which the epidural and subarachnoid space could be reached was studied. The optimal point of insertion was defined as the point where this range is the widest. The geometrical model clearly demonstrated, that the range of angles at which the epidural or subarachnoid space can be reached, is dependent on the point of insertion between the tips of the adjacent spinous processes. The steeper the spinous processes run, the more cranial the point of insertion should be. Assuming that the model is representative for patients, the performance of neuraxial blockade using a midline approach might be improved by choosing the optimal point of insertion.
\end{abstract}

Keywords: neuraxial blockade, midline approach, optimal point of insertion, geometrical model

\section{Introduction}

Neuraxial blockade using a midline approach can be technically difficult. This might be, eg, due to degenerative changes of the spine of the patient or due to a limited ability of the patient to flex his hips. It is usually performed after palpation of the tips of the spinous processes above and under the intended level of entry of the needle. Several factors have been implicated to determine the difficulty of the intended puncture. Both patient-related factors - eg, age, ${ }^{1}$ body mass index, ${ }^{1}$ deformities of the spine, ${ }^{2,3}$ the ability of the patient to flex his back, ${ }^{3}$ palpability of bony landmarks ${ }^{2,3}$ - and nonpatient-related factors - eg, equipment used, experience of the person performing the procedure, ${ }^{4}$ patient position chosen by the clinician ${ }^{1}$ - have been described in the literature. It would be very useful to know, how to optimize factors that are under the influence of the clinician performing the procedure because repeated attempts increase the incidence of complications and patient discomfort. ${ }^{5-7}$ One of these factors might be the optimal place to insert the needle. To the best of our knowledge, surprisingly few data exist on where between the tips of the spinous processes the needle should be introduced to approach the subarachnoid (SAS) or epidural space (ES) without bone contact (for simplicity, in the subsequent text we mean both the SAS and the ES, where
Correspondence: Martin Hagenaars Department of Anesthesiology, Canisius Wilhelmina Ziekenhuis, Weg door Jonkerbos 100, 6532 SZ Nijmegen, the Netherlands

$\mathrm{Tel}+3$ I 24365772 I

Fax +3I 243657352

Email m.hagenaars@cwz.nl 
only the ES is mentioned). Data on this subject would be very useful, eg, to instruct a resident how to perform neuraxial anesthesia when using a midline approach.

For example, Pitkänen ${ }^{8}$ gives no hint for an optimal point of insertion in Cousins et al's textbook of regional anesthesia. He advises to direct the needle at $10^{\circ}$ when performing lumbar spinal anesthesia. The same textbook ${ }^{9}$ advises " [...] insertion closer to the superior spinous process and with a slight upward angulation [...]" for lumbar epidural anesthesia and "[...] extreme upward angulation [...]" for epidural anesthesia in the mid-thoracic region. No further details are provided here. For thoracic epidural anesthesia, Brull et al ${ }^{10}$ point out that the distance travelled by the needle is modified by a more perpendicular angle. However, they do not suggest an optimal point of insertion at the different levels. According to Fettes et al, the needle should be introduced " [...] precisely in the mid-line, mid-way between the posterior spines $[\ldots]$ " for lumbar puncture. This suggestion is not substantiated by clinical or experimental data. ${ }^{11}$ In one paper it is suggested that puncture at the lumbar region should involve insertion of the needle at the superior aspect of the spinous process that lies inferior to the space to be entered. ${ }^{12}$ Here, too, the authors provide no further explanation for this approach.

We hypothesize that the point of insertion of the needle determines the range of angles at which the ES can be reached (explained in Figure 1). It is assumed, that the larger this range is, the bigger the chance of successfully reaching this space in one attempt. We have tested this hypothesis in a simple geometrical model.

\section{Methods}

\section{Geometrical model}

Figure 1 represents the model. Two adjacent spinous processes of two vertebrae (A) are represented by two parallelograms ([B], shaded areas).

The following variables were chosen in the model (Figure 1):

1. the angle $(\theta)$ of the spinous processes relative to the virtual skin ( $\mathrm{Sk})$.

2. The distance between two adjacent spinous processes (d).

3. The length of the spinous processes (L) perpendicular to the Sk.

The point where the needle is inserted is $\mathrm{P}_{\mathrm{i}}$. The range of angles at which the ES can be reached by the tip of the needle is represented by $\alpha$ (Figure 1).

Calculation of $\alpha$, Figure 2: Sk represents the patient's skin surface. Points A, B, C, and D represent the boundaries of the space between two adjacent spinous processes. Variables $\mathrm{x}$ and $\mathrm{y}$ were attributed to $\mathrm{A}, \mathrm{B}, \mathrm{C}$, and $\mathrm{D}$; for point $\mathrm{A}_{\mathrm{A}}$ and $\mathrm{y}_{\mathrm{A}}$, and similarly for $\mathrm{B}, \mathrm{C}$, and $\mathrm{D}$. The needle is inserted at point $\mathrm{P}_{\mathrm{i}}\left(\mathrm{x}_{\mathrm{Pi}}, \mathrm{y}_{\mathrm{Pi}}\right)$. All points were placed in a grid. The range of angles at which the ES can be reached is represented by $\alpha$ :

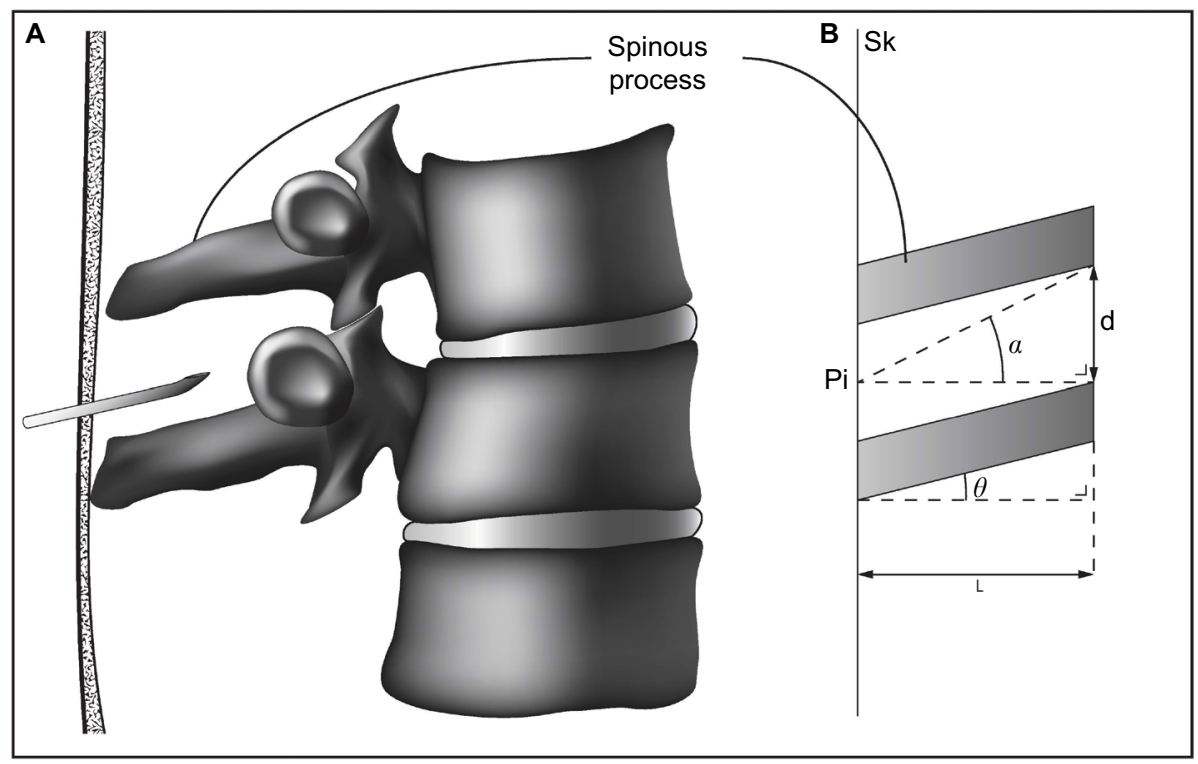

Figure I The adopted geometrical model: two adjacent spinous processes represented by two parallelograms.

Notes: Two adjacent spinous processes $(\mathbf{A})$ are represented by two parallelograms (B). The following variables were chosen in the model: $\theta$, $d$, and $L$, representing the angle of the spinous process relative to the skin (Sk), the distance between two adjacent spinous processes and the length of the spinous process perpendicular to the skin, respectively. $\alpha$ represents the range of angles at which it is possible to reach the epidural space by a needle inserted at point $P_{i}$. 


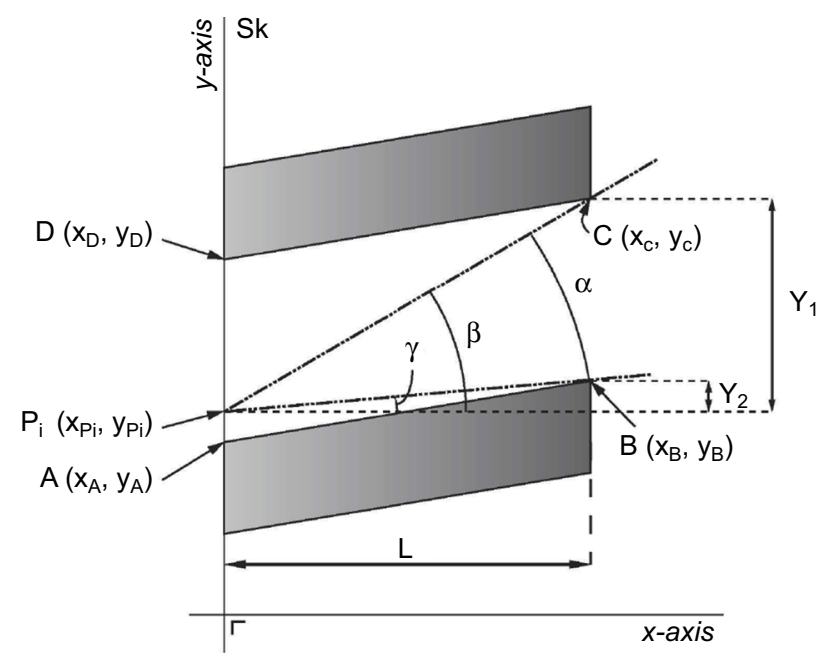

Figure 2 Two adjacent spinous processes are depicted (shaded areas).

Notes: The patient's skin surface is represented by Sk. Points A, B, C, and D represent the edges of the boundaries of the space between two adjacent spinous processes. Variables $x$ and $y$ were attributed to $A, B, C$, and $D$; for point $A x_{A}$ and $y_{B}$, and similarly for $B, C$, and $D$. The needle is inserted at point $P_{i}\left(x_{P_{i}}, y_{P_{i}}\right)$. All points were placed in a grid. The range of angles at which the epidural space or subarachnoid space can be reached is represented by $\alpha$, which was calculated as follows:

$\alpha=\beta-\gamma$

$\tan \beta=Y_{1} / L \Leftrightarrow \beta=\tan ^{-1}\left(Y_{1} / L\right)$, where $Y_{1}=y_{C}-y_{P_{i}}$;

$\tan \gamma=Y_{2} / L \Leftrightarrow \gamma=\tan ^{-1}\left(Y_{2} / L\right)$, where $Y_{2}=y_{B}-Y_{P_{i}}$

and

$$
\alpha=\beta-\gamma
$$

$$
\tan \beta=\mathrm{Y}_{1} / \mathrm{L} \Leftrightarrow \beta=\tan ^{-1}\left\{\mathrm{Y}_{1} / \mathrm{L}\right\}, \text { where } \mathrm{Y}_{1}=\mathrm{y}_{\mathrm{C}}-\mathrm{y}_{\mathrm{Pi}} ;
$$

$$
\tan \gamma=\mathrm{Y}_{2} / \mathrm{L} \Leftrightarrow \gamma=\tan ^{-1}\left(\mathrm{Y}_{2} / \mathrm{L}\right), \text { where } \mathrm{Y}_{2}=\mathrm{y}_{\mathrm{B}}-\mathrm{y}_{\mathrm{Pi}}
$$

The variables $\theta, \mathrm{d}$, and $\mathrm{L}$ were varied over a wide range, in order to be able to make solid statements of their effects on $\alpha ; \theta$ varied from $0^{\circ}$ to $72^{\circ}$. Calculations were performed in Excel spreadsheets (Microsoft Office, 2007). In all these various cases, $\alpha$ (y-axis) was plotted as a function of the points of insertion ( $\mathrm{x}$-axis, $\mathrm{P}_{\mathrm{i}}$ ) in diagrams. A total number of 196 spreadsheets were made. A representative selection of the results is shown in the results section. Data sets are available on request by email.

\section{Results}

In Figure 3A, C, E, G (left part) the angle $\theta$ (explained in Figure 1) is varied, resulting in a horizontal (Figure 3A) to steep (Figure $3 \mathrm{G}$ ) position of the spinous processes relative to the $\mathrm{Sk}$. In all these cases, $\alpha$ is maximal when $\mathrm{P}_{\mathrm{i}}$ is chosen at the point that is the projection of the point halfway between points $\mathrm{b}$ and $\mathrm{c}$ on the skin (explained more extensively in the figure). This optimal point of insertion is represented by $\mathrm{P}_{\mathrm{i}, \text { op }}$ in Figure 3C, E and G.

The corresponding plots, which vary in shape, are shown in Figure 3B, D, F, H (right part). When the spinous processes run horizontally, $\alpha$ is maximal when the point of insertion is chosen halfway between points a and d (Figure 3B). When $\theta$ increases, the point of insertion where $\alpha$ is maximal gradually shifts cranially, ie, $\mathrm{P}_{\mathrm{i} \text { opt }}$ approaches point $\mathrm{d}$.

In Figure $3 \mathrm{E}$ the point of insertion where $\alpha$ is maximal corresponds with point $d$. This means that when steeper angles $\theta$ are chosen than in this particular situation, $\mathrm{P}_{\mathrm{i}, \text { opt }}$ is consistently at point $\mathrm{d}$, ie, the most cranial point between two adjacent spinous processes (Figure $3 \mathrm{G}$ ).

According to this model, the chosen point of insertion between the spinous processes determines the value of $\alpha$. This dependency is most pronounced when the spinous processes run steeply. In the situation of Figure $3 \mathrm{H}$, the absolute increase of $\alpha$-when it is compared to the least favorable point of insertion, ie, point a (compare Figure $3 \mathrm{E}$ ) is $9^{\circ}$ (from $18^{\circ}$ to $27^{\circ}$ ), which is a relative increase of $50 \%$. For the situations of Figure $3 \mathrm{~B}, \mathrm{D}$, and $\mathrm{F}$, these numbers are $1^{\circ}$ and $4 \%, 4^{\circ}$ and $17 \%$, and $6^{\circ}$ and $27 \%$, respectively.

\section{Discussion}

Our geometrical model clearly demonstrated, that the range of angles at which the ES can be reached, is dependent on the point of insertion between the tips of the spinous processes when using a midline approach. Many anesthesiologists perform both lumbar and thoracic neuraxial blockade by using a midline approach. ${ }^{13}$ Therefore, this finding is relevant for daily anesthetic practice. Especially in patients where neuraxial anesthesia turns out to be technically difficult - eg, due to degenerative changes of the spine - choosing the optimal point of insertion may enhance the chance of successfully reaching the ES.

Although we studied the median approach in neuraxial anesthesia, some anesthesiologists advocate a paramedian approach. Comparative studies in the literature, we found, usually focused on the lumbar region of the spine. Indeed, some studies found an advantage for the paramedian approach eg, in terms of a higher success rate at the first puncture attempt, ${ }^{14}$ or time needed to reach the ES. ${ }^{15}$ Other studies, however, could not confirm that the paramedian approach is superior to the median approach. These studies were for example looking at predictors for success during the first puncture attempt ${ }^{7}$ or the incidence of post-dural puncture headache.${ }^{16}$ Apparently, more and larger studies are needed to answer the question 'which approach under what conditions should be preferred'.

According to our results, the optimal point of insertion of the needle shifts cranially when the spinous processes run steeper. Choosing a more cranial point of insertion of the needle will not only increase the range of angles at which the SAS and ES can be reached, but will also shorten the puncture route. 

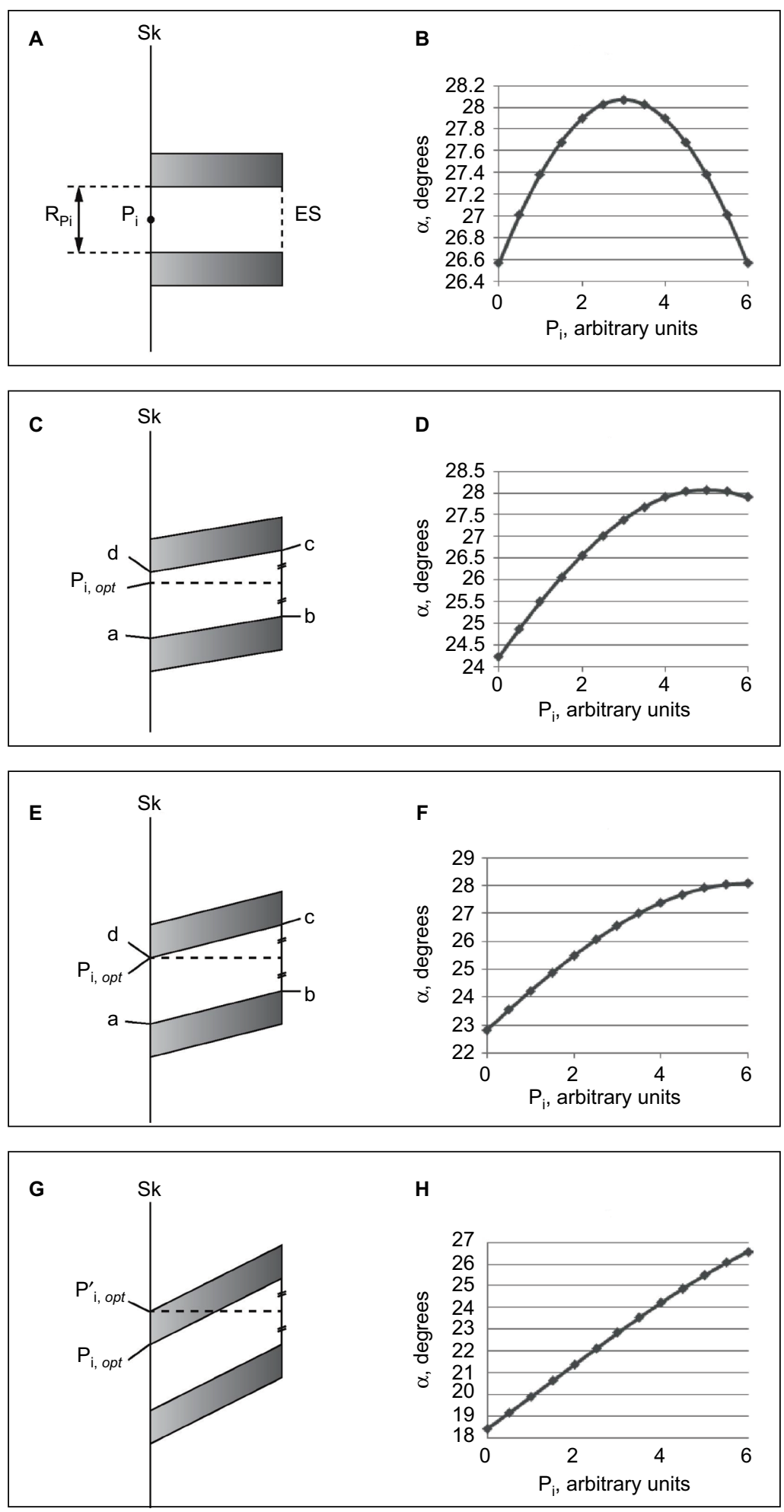

Figure 3 Four sets of two adjacent spinous processes and their corresponding plots are depicted.

Notes: Four sets (A, C, E, G) of two adjacent spinous processes are depicted (shaded areas). The right column shows the corresponding plots (B, D, F, and H). Sk (left part) represents the skin that directly overlays the tips of the spinous processes. $R_{p i}(A)$ represents the range on the Sk where the needle could be inserted. This range corresponds to the $\mathrm{x}$-axis in the corresponding plots (right part). Since only the relative sizes of the parts of the spinous processes are relevant for all calculations, we choose to express $\mathrm{Pi}$ on the $\mathrm{x}$-axis in arbitrary units. The lower the value of $\mathrm{P}_{i}$, the more caudally the needle is inserted. $P_{i}(\mathbf{A})$ represents an example of a place to insert the needle. To the right of the dotted line is the epidural space (ES) (A). In (C), the reconstruction of point $P_{i}$ where $\alpha$ is at its maximum is shown. The dotted horizontal line divides the interspinous space between point $b$ and $c$ in two equal parts. The projection of this line on the skin represents the point where $\alpha$ is at its maximum ( $P_{i, \text { opt }}$ ). Note that here, $P_{i, \text { opt }}$ is slightly caudally from the most cranial point of insertion that is possible (ie, point $d$ in [C]). The corresponding plot $(\mathbf{D})$ shows a top $\left(P_{i, \text { opt }}\right)$ and then declines. In (E), $P_{i, \text { opt }}$ corresponds to point $d$. This means that $\alpha$ is maximal when the needle is inserted at the most cranial point. When the spinous processes run even more steeply $(\mathbf{G})$, this projection coincides with a bony part of the spinous process $\left(\mathrm{P}_{\mathrm{i}, \text { opt }}\right)$ where insertion of the needle is not possible. Under these circumstances, $\mathrm{P}_{\mathrm{i} \text {, opt }}$ is, as in the situation in (E), at point $\mathrm{d}$. 
The borders of spinous processes are not smooth, straight lines in vivo and adjacent spinous processes do not run perfectly parallel to each other as in our model. However, these simplifications enabled us to make calculations and eventually enabled us to test our hypothesis that the point of insertion of the needle is an important determinant for the chance of reaching the ES.

Ultrasound imaging is increasingly used for neuraxial blockade. However, many - if not the majority of - anesthesiologists still use the landmark-guided technique, probably since it is relatively effective and the use of ultrasound requires additional skills. ${ }^{17}$ It would be of interest to investigate if ultrasound can be helpful to find the optimal point of insertion of the needle.

Previously, it has been shown that a change in flexion of the hips changes the curvature of the spine. ${ }^{18}$ Consequently, a change in the curvature of the spine, will probably also change the width between adjacent spinous processes. Indeed, several papers describe the influence of patient positioning on the interspinous space width in the lumbar region of the spine. ${ }^{19-22}$ We are not aware of studies of the thoracic region of the spine. For example, in the study by Fisher et al, the absolute increase in width between lumbar interspaces was $1 \mathrm{~mm}$ or less in $60 \%$ ( 21 of 35 measurements) of the studied cases and 1 to $2 \mathrm{~mm}$ in $31 \%$. The corresponding relative increases varied from $5 \%$ to $14 \%$ (cases with an absolute increase of $1 \mathrm{~mm}$ or less) and from $12 \%$ to $33 \%$ (cases with an absolute increase of 1 to $2 \mathrm{~mm}$ ). ${ }^{19}$ In the study by Sanodoval et al (when comparing the sitting position with unsupported feet to sitting with supported feet), the absolute increase in width between spinous processes was $1 \mathrm{~mm}$ or less in nine of 16 cases, 1 to $2 \mathrm{~mm}$ in four of 16 cases, and more than $2 \mathrm{~mm}$ in three cases (being 2.1, 2.4, and $3.6 \mathrm{~mm}$ respectively). ${ }^{20}$ Since our model did not take the role of patient positioning into account, our results should be interpreted with caution. On the other hand, as we discussed above, the changes in interspinous space width when changing from a position with no or limited hip flexion to more hip flexion seem to be limited, both in absolute and in relative numbers. Furthermore, the influence of changing patient positioning on the ease of performing a neuraxial blockade seems also to be limited. ${ }^{23-25}$ From the available data, it is difficult to predict how changes in the spinal curvature and forthcoming changes in the angulations of the spinous processes will affect the optimal point of needle insertion. Therefore, it is worthwhile to test the findings in our model in patients, both with and without flexion of their hips. Results from these future studies may further substantiate a scientific rationale, how to perform neuraxial anesthesia when using a midline approach.

\section{Acknowledgment}

The authors wish to thank Koen Terra MSc for preparation of the figures.

\section{Disclosure}

The authors report no conflicts of interest in this work.

\section{References}

1. Ruzman T, Gulam D, Harsanji Drenjancevic I, Venzera-Azenic D, Ruzman N, Burazin J. Factors associated with difficult neuraxial blockade. Local Reg Anesth. 2014;7:47-52.

2. Atallah MM, Demian AD, Shorrab AA. Development of a difficulty score for spinal anaesthesia. Br J Anaesthesia. 2004;92(3):354-360.

3. Guglielminotti J, Mentré F, Bedairia E, Montraves P, Lamgrois D. Development and evaluation of a score to predict difficult epidural placement during labor. Reg Anesth Pain Med. 2013;38(3):233-238.

4. Kim JH, Song SY, Kim BJ. Predicting the difficulty in performing a neuraxial blockade. Korean J Anaesthesiol. 2011;61(5):377-381.

5. Puolakka R, Haasio J, Pitkänen MT, Kallio M, Rosenberg PH. Technical aspects and postoperative sequelae of spinal and epidural anesthesia: a prospective study of 3,230 orthopedic patients. Reg Anesth Pain Med. 2000;25(5):488-497.

6. Kang XH, Bao FP, Xiong XX, et al. Major complications of epidural anesthesia: a prospective study of 5083 cases at a single hospital. Acta Anaesthesiol Scand. 2014;58(7):858-866.

7. de Filho GR, Gomes HP, da Fonseca MH, Hoffman JC, Pederneiras SG, Garcia JH. Predictors of successful neuraxial block: a prospective study. Eur J Anaesthesiol. 2002;19(6):447-451.

8. Pitkänen M. Spinal (subarachnoid) blockade. In: Cousins MJ, Carr DB, Horlocker TT, Bridenbaugh PO. Cousins and Bridenbaugh's neural blockade in clinical anesthesia and pain medicine. 4th ed. Lippincott Williams \& Wilkins; 2009:213-240.

9. Veering BT, Cousins MJ. Epidural neural blockade. In: Cousins MJ, Carr DB, Horlocker TT, Bridenbaugh PO. Cousins and Bridenbaugh's neural blockade in clinical anesthesia and pain medicine. 4th ed. Lippincott Williams \& Wilkins; 2009:241-295.

10. Brull R, MacFarlane AJ, Chan VW. Spinal, Epidural and Caudal Anesthesia. In: Miller's anesthesia. $8^{\text {th }}$ ed. Philadelphia, PA: Elsevier Saunders; 2015:1684-1720.

11. Fettes PD, Jansson JR, Wildsmith JA. Failed spinal anaesthesia: mechanisms, management, and prevention. Br JAnaesth. 2009;102(6): 739-748.

12. Boon JM, Abrahams PH, Meiring JH, Welch T. Lumbar puncture: anatomical review of a clinical skill. Clin Anat. 2004;17(7):544-553.

13. Wantman A, Hancox N, Howell PR. Techniques for identifying the epidural space: a survey of practice amongst anaesthetists in the UK. Anaesthesia. 2006;61(4):370-375.

14. Rabinowitz A, Bourdet B, Minville V, et al. The paramedian technique: a superior initial approach to continuous spinal anesthesia in the elderly. Anesth Analg. 2007;105(6):1855-1857.

15. Leeda M, Stienstra R, Arbous MS, et al. Lumbar epidural catheter insertion: the midline vs. the paramedian approach. Eur JAnaesthesiol. 2005;22(11):839-842.

16. Mosaffa F, Karimi K, Madadi F, Khoshnevis SH, Daftari Besheli L, Eajazi A. Post-dural puncture headache: a comparison between median and paramedian approaches in orthopedic patients. Anesth Pain Med. 2011;1(2):66-69.

17. Chin KJ, Karmakar MK, Peng PP. Ultrasonography of the adult thoracic and lumbar spine for central neuraxial blockade. Anesthesiology. 2011; 114(6):1459-1485.

18. Stokes IA, Abery JM. Influence of the hamstring muscles on lumbar spine curvature in sitting. Spine (Phila Pa 1976). 1980;5(6):525-528.

19. Fisher A, Lupu L, Gurevitz B, Brill S, Margolin E, Hertzanu Y. Hip flexion and lumbar puncture: a radiological study. Anaesthesia. 2001; 56(3):262-266. 
20. Sandoval M, Shestak W, Stürmann K, Hsu C. Optimal patient positioning for lumbar puncture, measured by ultrasonography. Emerg Radiol. 2004;10(4):179-181.

21. Abo A, Chen L, Johnston P, Santucci K. Positioning for lumbar puncture in children evaluated by bedside ultrasound. Pediatrics. 2010;125(5): e1149-1153.

22. Capogna G, Celleno D, Simonetti C, Lupoi D. Anatomy of the lumbar epidural region using magnetic resonance imaging: a study of dimensions and a comparison of two postures. Int J Obst Anesth. 1997;6(2): 97-100.
23. Fisher KS, Arnholt AT, Douglas ME, Vandiver SL, Nguyen DH. A randomized trial of the traditional sitting position versus the hamstring stretch position for labor epidural needle placement. Anesth Analg. 2009; 109(2):532-534.

24. Mohammadi SS, Hassani M, Marashi SM. Comparing the squatting position and traditional sitting position for ease of spinal needle placement: a randomized clinical trial. Anesth Pain Med. 2014;4(2):e13969.

25. Biswas BK, Agarwal B, Bhattarai B, Dey S, Bhattacharyya P. Straight versus flex back: Does it matter in spinal anaesthesia? Indian J Anaesth. 2012;56(3):259-264
Local and Regional Anesthesia

\section{Publish your work in this journal}

Local and Regional Anesthesia is an international, peer-reviewed, open access journal publishing on the development, pharmacology, delivery and targeting and clinical use of local and regional anesthetics and analgesics. The journal is included in PubMed, and welcomes submitted papers covering original research, basic science, clinical studies,

\section{Dovepress}

reviews and evaluations, guidelines, expert opinion and commentary, case reports and extended reports. The manuscript management system is completely online and includes a very quick and fair peer-review system, which is all easy to use. Visit http://www.dovepress.com/ testimonials.php to read real quotes from published authors. 